\title{
Kant: Esclarecimento e Educação Moral
}

\author{
Kant: Enlightenment and Moral Education
}

\author{
Edmilson Menezes \\ ed.menezes@uol.com.br \\ (Universidade Federal de Sergipe, Sergipe, Brasil)
}

Resumo: 0 artigo procura avaliar o nexo entre Esclarecimento e educação moral em Kant a partir do seguinte pressuposto: é impossível pensar um homem esclarecido que não seja educado, também é difícil pensar alguém educado que não busque esclarecer-se, isto é, exercer livremente sua capacidade de pensar consequentemente. 0 círculo formado garante uma continuidade que aprimora, incessantemente, 0 ideal moral de humanidade.

Palavras- chave: Kant, educação moral, Esclarecimento.
Abstract: This article seeks to evaluate the nexus between Enlightenment and moral education in Kant's view, based on the assumption that it is impossible to think about an enlightened man who is not educated, as well as it is difficult to think about someone who is educated but is not seeking to enlighten himself, that is, exercise his skills to reasoning freely. The circle formed by this connection guarantees a continuity that enhances mankind moral ideal endlessly.

Keywords: Kant, moral education, Enlightenment.

DOI: http://dx.doi.org/10.11606/issn.2318-9800.v19i1p117-147

Século XVIII: Educação, um affaire público e esclarecido.

Quando Gusdorf declara que o século XVIII é o "século da pedagogia", ${ }^{1}$ sua expressão destaca uma das faces de maior influência

1. GUSDORF, G. L'avènement des Sciences Humaines au siècle des Lumières. Paris: Payot, 1973 , p. 155. Embora reconheçamos, com Husserl, para continuarmos no âmbito contemporâneo, alguns de seus aspectos mais notáveis ("o século autodenominado o século filosófico, atingiu os mais vastos domínios, entusiasmou-se pela filosofia e por todas as ciências particulares enquanto ramificações dela. Além disso, o fervor e o impulso em direção à cultura, o zelo pela reforma filosófica da educação e do conjunto das formas sociais e polí- 


\section{Edmilson Menezes}

desse século fascinado pela "arte de educar". Nele, encontramos um grupo de questões do qual o nosso tempo continua a se nutrir quando se trata de avaliar, compreender ou organizar o processo pelo qual se educa a humanidade, entendida como o conjunto dos seres dotados de razão e passíveis de aperfeiçoamento. Boa parte das reflexões desse período, acerca dos problemas educacionais, encontra-se reunida por uma de suas grandes manifestações intelectuais, a saber, o Iluminismo, quer seja em sua versão Alemã, a Aufklärung (Esclarecimento), quer seja em sua expressão francesa, as Lumières (as Luzes, ou Ilustração). ${ }^{2}$ Entre 1750 e 1760, um movimento ascendente impregna as mentes com um problema incontornável: "parece que, em relação aos objetivos da educação, há, no público da Europa, uma espécie de fermentação, que deve produzir bons efeitos". ${ }^{3}$ Enquanto "fermentação" intelectual, ele tenta buscar verdades e exaltar a capacidade de encontrá-las, transmiti-las ou reformulá-las pela educação: "o espírito continua incansável e sem desânimo em suas aspirações de verdade e educação, até que a morte ponha fim a seus nobres esforços. ${ }^{\prime 4}$ Se a morte pode pôr termo aos esforços pessoais de aperfeiçoamento, o seu triunfo esbarra na imortalidade da espécie. Por isso, a educação não é um affaire somente da pedagogia ou da escola, isto é, educar extrapola um conjun-

ticas da humanidade, fazem da época da Aufklärung, se frequentemente depreciada, também uma época digna de ser honrada." [HUSSERL, E. Die Krisis der europäischen Wissenschaften und die transzendentale Phänomenologie. In: Gesammelte Werke (Husserliana VI). Hagg: Martinus Nijhoff, 1976, pp. 7-8] ), o Século XVIII não se resume a rubrica única. Na verdade, ele é um artifício intelectual. A fim de tentar resistir à comodidade trazida pelas grandes generalizações, é preferível reconhecer a heterogeneidade do Século XVIII, o que não implica recusar a continuidade exigida pela pesquisa histórica, e encarar seus grandes temas como hipóteses de trabalho e não como uma essência daquele movimento.

2. O emprego dos termos Esclarecimento, esclarecer, esclarecido ficará jungido às referências sobre a Aufklärung, enquanto os termos Ilustração, ilustrar e ilustrados estarão associados às Lumières. Para as remissões aos dois movimentos em conjunto, as palavras Iluminismo e seus derivados serão utilizadas.

3. CARADEUC DE LA CHALOTAIS, L-R. Essai d'éducation nationale ou Plan d'études pour la Jeunesse. Genève: Cl. \& Ant. Philibert, 1763, p. 36.

4. RIEM, A. Über Aufkärung (1788) In: BATSCHA, Z. Aufklärung und Gedankenfreibeit, FunfzebnAnregungen, aus der Geschicbte zulernen. Frankfurt: Suhrkamp, 1977, p.119. 
to de técnicas e um espaço físico. Não é só o indivíduo físico que requer métodos de ensino e aprimoramento. Educa-se, também, o homem enquanto espécie, de modo a nele se manter, em equilíbrio, a moral e o pendor natural: "a natureza estabelece a diferença entre os homens, disso não se pode duvidar, a educação a estabelece talvez muito mais. ${ }^{15}$ Para a filosofia iluminista, essa passagem da natureza à cultura é mediada pela civilização; ela se situa entre a vida natural, rude, própria da primeira, e um estágio superior, concebido com base num progresso constante. $O$ ponto distintivo, para essa filosofia, radica no seguinte aspecto: espera-se que da vida civil chegue-se à moralidade e, para que a espécie aí se localize, a educação é indispensável. ${ }^{6}$ Logo, a pedagogia e a educação receberão as luzes da filosofia, que fará delas um alvo privilegiado, propondo, para ambas, uma reforma. Além de ser concebida como um problema prático, a educação, também, é um problema que se impõe teoricamente ao espírito. Pudéssemos às expressões de D'Alembert ("Nosso século é chamado, por excelência, o século da filosofia.")7e de Fabricius ("Vivemos um verdadeiro século da educação") ${ }^{8}$ aditar uma terceira, ela seria: o século XVIII é o século da Filosofia da Educação.

Segundo Hegel, "o direito da particularidade do sujeito a encontrar sua satisfação, ou, o quer dizer o mesmo, o direito da liberdade subjetiva, constitui o centro que marca a diferença entre a Antiguidade e os Tempos modernos(modernen Zeit) ${ }^{\prime \prime}{ }^{9}$ a liberdade notabiliza a Modernidade como o único período da história que se autodefine, que usa da liberdade em seu grau absoluto para construir-se. O movimento pressuposto na própria ideia de construção abre o flanco à educação:

5. CARADEUC DE LA CHALOTAIS, L-R.Essai d'éducation nationale ou Plan d'études pour la Jeunesse, p. 8 .

6. Sobre o nexo positivo entre vida civil e moralidade, há a abordagem discordante de Rousseau, ver: ROUSSEAU, J-J. Discours sur les sciences et les arts (1750) In: Oeuvres Complètes. Paris: Gallimard, 1996. Tome III: Écrits Politiques. (Bibliothèque de la Pléiade).

7. D'ALEMBERT. Essaisur les éléments de pbilosopbie (1759). Paris: Fayard, 1986, p. 10.

8. FABRICIUS, J. C. Von der Erziehung in sonderheit in Danemark. DessauLeipzig. In: KOENIG, H. Zur Geschichte der Nationaler ziebung in Deutschland im letzten Drittel des 18. Jabrbunderts. Berlim: Akademie Verlag, 1960, p. 40.

9. HEGEL, G.W.F. Grundlinien der Pbilosopbie des Recbts (§ 124). Hamburg: Felix Meiner, 1955, p.112. 


\section{Edmilson Menezes}

a cada movimento, uma aprendizagem, e, a cada aprendizagem, um progresso. Não há verdadeira liberdade sem educação, pois ela nos torna o que somos: "a educação dá ao homem dignidade". ${ }^{10} \mathrm{O}$ que é ser digno? Como entender a condição de quem porta dignidade? Ser digno é tornar-se referência de si mesmo, é torna-se referência para si mesmo. No reino dos fins, tudo tem um preço ou uma dignidade - lembra-nos Kant. Quando uma coisa tem um preço, pode-se pôr, em vez dela, qualquer outra como equivalente; mas quando uma coisa, ao contrário, é superiora todo preço, e, portanto, não admite equivalente, então ela tem uma dignidade. ${ }^{11}$ Em sua singularidade, nenhum homem pode ter um preço estipulado quando se trata da moral: o incondicionado, por ser independente, não pode ser taxado. $\mathrm{O}$ que se relaciona com as inclinações e necessidades gerais do homem, o que, mesmo sem pressupor uma necessidade, é conforme a certo gosto, à sofisticação no jogo livre e sem finalidade das nossas faculdades anímicas, tem seu preço. $\mathrm{O}$ que, porém, constitui a condição graças a qual qualquer coisa pode ser um fim em si mesma, não tem só um valor relativo, ou seja, um preço, mas um valor íntimo, uma dignidade. Só os seres racionais são passíveis de dignidade, e o homem, por sua capacidade de autorreferência e de, também, referir-se a seus pares, torna-se o maior e único grau deste valor intrínseco. A razão relaciona cada máxima da vontade, concebida como legisladora universal, com todas as outras vontades e todas as ações para conosco. Isto não se dá em virtude de qualquer outro motivo prático ou vantagem futura, mas por causa da própria ideia de dignidade de um ser que não obedece outra lei senão a que ele mesmo se dá. Nada equivale a um homem, salvo outro homem. Por isso, no convívio das liberdades, os homens devem, uns aos outros, o respeito merecido em toda singularidade, por ser digna, por ser fim em si mesma.

O homem dos tempos modernos - aquele que se reconhece em sua singularidade -é capaz de interrogar-se sobre si mesmo e situar-se

10. DIDEROT, D. Plan d'uneuniversité pour le gouvernement de Russieou de l'éducation publique dans toutes les sciences (1775-1776). In: Oeuvres Complètes (Tome III). Paris: Garnier, 1875, p. 429.

11. KANT, I. Grundlegung zur Metaphysik der Sitten. In: Kant's gesammelte Scbriften, v. IV, 434-435. Herausgegeben von der Königlich Preussischen Akademie der Wissenschaften, v.23 (Doravante indicada pela sigla AK. Os algarismos romanos remetemao volume e os arábicos, às páginas dessa edição). 
entre a barbárie, que abandonou, e a moralidade, que precisa alcançar para melhor viver em sociedade. Diverso de outros períodos, a Modernidade apresenta a noção de sujeito que, além da capacidade de produzir evidências fundadoras de um conhecimento teórico, identifica-se como agente capaz de ordenar-se livremente em vista de uma consecução moral. A formação desse bomem geral é o alvo das análises da filosofia da educação moderna. Porque são obrigados a conviver, e essa convivência precisa ser pautada no respeito ao outro - como fonte intrínseca de dignidade - para que se cumpramos verdadeiros intentos da espécie, os homens necessitam aprender como retirar o melhor proveito da vida em comum, na qual todos são equivalentes a todos em liberdade.

Talvez a educação seja uma das poucas causas unânimes no controvertido e complexo movimento iluminista. Os intelectuais deste período não têm as mesmas opiniões sobre ela, como fomentá-la ou sobre os resultados dela advindos. Porém, todos, de uma forma ou de outra, envolvem-se com o tema e acreditam que formar o homem é tarefa relevante e urgente. O educador é, por sua tarefa, o Aufklärer por excelência: existe a tarefa premente de conduzir os homens à maioridade, preservando-os dos tutores externos. A filosofia da educação esclarecida prima por fortalecer uma ideia de sujeito, criação do homem por ele mesmo; formar, transformar sua natureza. Para levar a efeito tão grande tarefa, os educadores, também sob o influxo das ideias filosóficas, centram seus esforços na formação do indivíduo livre. Muito mais do que uma postura intelectual, a educação vai receber dos homens esclarecidos um cunho militante e ativo: a educação se transforma num affaire público, que se impregna de um debate candente e intelectualizado contra os modelos pedagógicos até então vigentes. Todavia, a polêmica pública vai procurar seu respaldo longe da contenda acalorada dos grandes embates, ela será apoiada por um princípio filosófico caro ao Século XVIII: o princípio da autonomia. O homem esclarecido é aquele autônomo, capaz de guiar-se a si mesmo, mas que precisa conviver com outros homens, precisa ser educado. Nesse sentido, um projeto de emancipação e esclarecimento pede, fundamentalmente, uma ideia de educação e um projeto pedagógico que possam ser debatidos.

Há uma certeza de que se vive num século especial, num século filosófico e educado; e essa confiança no presente - momento mais esclarecido do que as épocas anteriores -deveria apressar a nossa marcha. A história trazia os exemplos a serem seguidos ou rejeitados: 


\section{Edmilson Menezes}

"Os séculos os mais grosseiros e os mais ignorantes foram sempre os mais viciados e os mais corrompidos. Deixem o homem sem cultura, ignorante e, consequentemente, insensível aos deveres, e ele se tornará fraco, supersticioso, talvez cruel. Se não the ensinam o bem, ele se ocupará, necessariamente, do mal. O espírito e o coração não podem permanecer vazios."12 $\mathrm{O}$ conteúdo que ali deve ser depositado é o conjunto de conhecimentos e valores amealhados pelos homens em sua história. No entanto, se esse conteúdo assume uma feição monolítica e intransigente, ele não desempenhará, de forma adequada, sua função, porque deixou de servir também ao presente. Para o pensamento moderno, a educação deve refletir o progresso e vice-versa. Sendo assim, a capacidade indefinida de educar-se é o vetor do progresso, ela fornece a base para uma crença mínima num plano de conjunto da evolução humana, de um progresso geral rumo ao melhor; ao mesmo tempo, o progresso é medido pelo quantum de educação e instrução somadas por um povo em sua trajetória. A tal nexo, deve a Modernidade uma de suas características mais destacadas.

Contudo, mais um realce a notabiliza entre outras épocas, também cônscias da importância do ato educativo: os modernos tornam o debate sobre a educação, um debate público. Sua companheira: a polêmica savante e filosófica. "Os filósofos pedem contas aos pedagogos, e as julgam mal feitas, recomeçam; eles se valem de Montaigne, de Fénelon e de Locke, cuja influência é particularmente forte — caso particular de uma ação geral. Todos irão examinar se as ideias do Sage - a educação destinada não mais a formar des bonnêtes gens, ornamento da Sociedade, porém cidadãos ativos; educação destinada a produzir corpos vigorosos e, ao mesmo tempo, almas retas; educação destinada a favorecer os poderes espontâneos do ser antes mesmo de constrangê-los - devem ser rejeitadas ou aceitas em vista de um futuro próximo." ${ }^{13}$ Os filósofos são consultados e intervêm prontamente, dando a conhecer proposições e orientações: "Eu era regularmente sondado, nestes últimos tempos, por pessoas que declaravam não saber como educar suas crianças e, por outro lado, a corrupção da juventude tornou-se motivo geral de lamentações, que me parece não se

12. CARADEUC DE LA CHALOTAIS, L-R. Essai d'éducation nationale ou Plan d'études pour la Jeunesse, p.7.

13. HAZARD, P. La pensé européenne au XVIIIe. Siècle de Montaigne à Lessing. Paris: Fayard, 1963, p. 192. 
poder qualificar de impertinente a empresa daquele que convoca, a esse propósito, a atenção do público e propõe certas reflexões pessoais sobre a matéria, com a intenção de exercitar os esforços de outrem e de provocar sua crítica. Com efeito, os erros oriundos da educação são os que merecem menos indulgência. Como os defeitos da primeira cozedura da faiança, que só serão corrigidos na segunda ou na terceira, aqueles erros deixam atrás de si uma marca incorrigível, cujo traço subsiste durante todas as partes e períodos da vida. ${ }^{14} \mathrm{As}$ intervenções dos grandes pensadores estão, como não poderia deixar de ser, atreladas às suas respectivas filosofias e estruturam-se sob o entusiasmo de um debate direto e de uma circulação de ideias entre sábios ${ }_{i}{ }^{15}$ o que confere a essa parte da obra pedagógico-filosófica uma feição pública. Ela se revela num "campo de batalha" público no qual se conflitam os interesses teóricos e práticos de propostas educativas diferentes. Quando se trata de expor as implicações morais e políticas da educação, essa fatura pública participa da liberdade de expressão filosófica, e oferece uma contribuição mais direta ao debate em torno dos temas expressivos da história da educação.

Vejamos mais dois pronunciamentos significativos: "É um fato inegável que temos trabalhado muito, nestes últimos tempos, para o aperfeiçoamento de nosso sistema educativo. Nós vivemos um verdadeiro século da educação (Erziebungsjabrundert). Vimos os Philantbropinum e outras instituições educativas de diferentes espécies nascerem e desaparecerem. Duas vezes por ano, somos afogados por uma massa inumerável de escritos pedagógicos; possuímos semanários e almanaques para os pais e crianças"16. O erudito alemão nos coloca diante de um quadro revelador: a educação, como um problema teórico e prático, impõe-se ao período na forma de variadas propostas metodológicas e de estabelecimentos de ensino, fato que não admite a menor dúvida quanto ao reconhecimento da importância da matéria em sua

14. LOCKE, J. Some Thoughts concerning Education (1693). In: The Works of Jobn Locke. London: Reprinted by Scientia Verlag Aalen, Darmstadt, 1963. v. IX, p. iv.

15. Sobre as ideias que estão em jogo na discussão dos escritos de Locke sobre educação, ver: DUNN, J. The Political Thoughtof Jobn Locke. Cambridge: Cambridge University Press, 1969 (Cap. X).

16. FABRICIUS, J. C. Von der Erziehung in sonderheit in Danemark, pp. 40-41. 
diversidade. O homem esclarecido é convidado a intervir publicamente acerca de procedimento tão crucial.

Nos países civilizados da Europa não faltam estabelecimentos de ensino, assim como o zelo bem intencionado dos mestres, sobre este ponto, está a serviço de todos, e, no entanto, encontra-se, hoje, claramente demonstrado que, como lá se trabalha num sentido contrário à natureza, estamos bem longe de produzir no homem o bem para o qual a natureza o predispôs; pois, na condição de criaturas animais, somente ascendemos à humanidade pela cultura. Veríamos ao nosso redor, em pouco tempo, homens muito diferentes daquilo que são, se o método educativo geralmente em uso fosse tirado da própria natureza, ao invés de imitar servilmente os velhos hábitos de épocas grosseiras e inexperientes. Porém, seria vão esperar salvação da espécie humana de uma melhora gradual das escolas. É preciso que elas sejam completamente modificadas, se queremos nelas ver alguma coisa de bom, porque estão defeituosas em sua organização primeira e, os próprios mestres, precisariam receber uma nova formação. Esse intento não pode ser atingido por meio de uma lenta reforma, é preciso uma imediata revolução. ${ }^{17}$

Avesso a revoluções no campo político stricto sensu, Kant parece não recusá-las ao campo educativo ${ }^{18}$; a urgência em suplantar "os velhos hábitos", isto é, a erudição estéril do classicismo ou do sistema religioso de ensino, possui sua base na crítica desferida à ausência, naqueles hábitos, do cultivo moral efetivo, dito de outra forma, do preparo, pela educação, à autonomia do homem. Uma nova escola e uma nova educação são, consequentemente, reclamadas.

O educador e o filósofo estão em consonância: a educação deve ser discutida e seus títulos norteadores trazidos a público, com o fito de se avaliar as consequências oriundas de vícios e impedimentos transmitidos, até o momento, pelas doutrinas ligadas ao atraso: "A educação, hoje, tende, evidentemente, a só fabricar escravos supersticiosos. ${ }^{19}$ Entre as ortodoxias, que alimentam e conservam a escravidão supersticiosa, uma das mais criticadas é a jesuítica; ela

17. KANT, I. Aufsätze das Philanthrop in betreffend, 1777.AK II, 449.

18. Ver, por exemplo, KANT, I. Metaphysik der Sitten (Rechtslehre), I, § 49, A. AKVI, 321-323.

19. D'HOLBACH, P-H. Th. "Lettres à Eugénie" (1768). In: Oeuvres philosopbiques. Paris: Alive, 1998, p. 453.t. I, lettre 11 
encarna, com propriedade, aquilo que a Ilustração julgará o mais perigoso, a saber, o monopólio da consciência moral, transformada, na esfera educacional, em consciência religiosa.

A moral é feita para regular sem divisão a sorte dos homens; a virtude é a coisa mais notável para eles, ela deve comandar os príncipes, regrar os governantes, dirigir a legislação, manter a sociedade, fixar o direito dos povos, ser a verdadeira bússola das nações e dos indivíduos. Ela basta para os tornar felizes: ela possui, então, direito a homenagens, culto, obediência e respeito. [...]Em uma palavra, a moral é a única religião necessária aos homens. ${ }^{20}$

Deve-se recusar a fé para consolidar a vida moral, pois a religião vicia a moral ao impedir qualquer estabelecimento livre, por parte dos homens, de regras para a sua autorregulação. Sabemos pela religião cristã: Nolite diligere mundum, neque ea qua in mundo sunt. ${ }^{21}$ No caso exemplar, amoral propalada é um conjunto de regras estribadas num outro mundo, sem que delas tenhamos consentido a declaração. Diz o Barão d'Holbach:

A moral cristã é verdadeiramente uma moral de outro mundo. [...] Ela tem por objeto desencorajar os fieis da Terra, para ligá-los unicamente a um céu, do qual não têm a menor ideia. [...]Para merecermos ser felizes nesse mundo desconhecido, [...]devemos interditar o uso da nossa razão, quer dizer, fechar os olhos para nos deixar guiar, como um cego, pelos padres. ${ }^{22}$

Estamos diante de uma moral antissocial. Se a sociedade subsiste é porque a moral do Evangelho não é praticada. E não o é, porque ela é falsa, se tivesse sido seguida, levaria as nações à ruína. Para a humanidade, é preciso uma moral social. "Importante é bem distinguir a moral religiosa da moral política: a primeira produz santos, a outra, cidadãos" ${ }^{23}$ Daquela, nascem os homens inúteis ao mundo; a outra,

20. D'HOLBACH, P-H. Th. "La contagion sa créeou Histoire naturelle de la superstition" (1768). In: Oeuvres pbilosopbiques. t. I, p. 278. Cap. XIII.

21. I Epístola de João 2, 15 (Não ameis o mundo nem o que nele há).

22. D'HOLBACH, P-H. Th. Lettres à Eugénie (1768), p. 399.

23. D'HOLBACH, P-H. Th. Le christianis medévoiléou Examen des principes et des effets de la religion chrétienne (1756), Préface. In: Oeuvres pbilosopbiques. t. I, p. 9. 


\section{Edmilson Menezes}

deve ter por objetivo formar cidadãos úteis à sociedade, ativos, capazes de cumprir seus deveres por amor ao bom senso. Com efeito, é certo que o homem é um ser sociável e que em tudo busca sua felicidade $_{i}$ que ele faz o bem quando ai encontra seu interesse, e, nessa procura, ele é, mais das vezes, mau, quando seu interesse é contrariado. "Isso posto, que a educação ensine os homens a conhecer as relações que subsistem entre eles e os deveres oriundos dessas relações; que os governos, com a ajuda das leis, das recompensas e das penas, confirmem as lições que a educação tenha dado." ${ }^{24} \mathrm{~A}$ educação moral é assunto independente das noções sublimes da teologia e não possui nenhum vínculo indissociável com a religião, mas a sociedade não terá nada a perder com semelhante investida, pois ela tem por meta formar homens capazes de, em seu mundo, entender que a felicidade acompanha as ações úteis e virtuosas; que a vergonha, o desprezo e o castigo seguem de perto o crime e o vício. A educação une-se a uma moral humana fundada sobre sua própria natureza, as necessidades das nações, os interesses das gentes e do governo.

Quando os cidadãos receberem uma educação honesta, que lhes inspire o zelo pelo princípio virtuoso, eles entenderão que só se chega à honra e à distinção pelos talentos e pelas virtudes. O corolário da boa conduta não é a recompensa prometida para o além do mundo; ele, ao contrário, estabelece-se numa sociedade que visa o bem coletivo e, nesse bem, encontra-se a realização. Enquanto as escolas estiverem sob o julgo do negócio religioso, uma formação dirigida ao interesse geral parece impossível. "É, sem dúvidas," diz Diderot,

bastante estranho que as escolas de educação pública bárbaras e góticas se mantenham, com todos os seus defeitos, no centro de uma nação esclarecida (éclairée), ao lado de três Academias, após a expulsão do maus mestres conhecidos pelo nome de Jesuítas, malgrado a constante reclamação - de toda a ordem-do Estado, em detrimento da nação, para sua vergonha, com prejuízo dos primeiros anos de toda a juventude de um reino e ao desprezo de uma série de obras excelentes, ao menos quanto a parte com a qual podemos contar para demonstrar os vícios dessa educação. ${ }^{25}$

24. Idem, ibidem.

25. DIDEROT, D. Plan d'une université pour le gouvernement de Russie ou de l'éducation publique dans toutes les sciences (1775-1776), p. 440. Todas as reservas feitas aos contextos eclesiástico e social dos sistemas pedagógicos existentes tinham 
A crítica diderotiana à Ratio Studiorum jesuítica vincula-se a um contexto maior de uma censuraa uma sociedade que, aos olhos do filósofo ilustrado, exige transformação. A começar por reconhecer na educação um enjeu importante ligado ao poder e à política. A educação não é somente um problema pedagógico, prático. $\mathrm{O}$ sentido amplo e o sentido técnico devem coincidir de modo que a ação de educar seja também uma postura política - eis outro ponto nevrálgico da proposta esclarecida. Educar o homem é, desse modo, organizá-lo para a vida em comum: da forma como for educado, também será o homem disposto na ordem social. Definir uma política no domínio pedagógico, pondera Baczco, referindo-se ao período posterior às Luzes, é escolher modelos formadores de cultura, de moral, etc. De pronto, as relações entre pedagogia e política e, notadamente, entre educação e poder, são particularmente complexas. ${ }^{26}$

Para entendermos melhor o descrédito para com o modelo religioso, é imperioso assinalar algo sobre tão formidável adversário: o sistema de educação adotado pelos jesuítas em sua Ratio Studiorum, aplicado com uma uniformidade rigorosa em todos os países católicos, cosmopolita e inalterável como a ordem da qual ele emanava, claro, lógico, preciso nos meios como nos fins, recomendado pelo sucesso e sustentado pela autoridade da Igreja, representava, aos olhos do público e mesmo dos pedagogos protestantes, a perfeição e a segurança, e tornava, consequentemente, toda tentativa de reforma inútil

suas críticas agrupadas em torno de alguns pontos principais. O primeiro é o exotismo latino do colégio. O latim permanece a língua do ensino, a despeito da formação das nações independentes, e de cada uma ter sua cultura própria e sua especificidade religiosa. Existe, na verdade, um ensino rudimentar, primário, dispensado pelas pequenas escolas; elas mal conseguem ensinar a ler e a escrever a uma parte da população infantil, em ligação com o pároco ou o pastor, que asseguram uma instrução religiosa pouco aprofundada. Todavia, esse ensinamento popular, que atinge, segundo o país, entre 10 e $30 \%$ dos habitantes, só representa um minimum intelectual. Trata-se de uma aprendizagem técnica como outra qualquer, conforme a utilidade social adaptada a um povo inteiramente iletrado. Cf. GUSDORF, G. L'avènement des Sciences Humaines au siècle des Lumières.., p. 129.

26. BACZKO, B. Une éducation pour la démocratie. Textes et projets de l'époque révolutionnaire. Genève: Droz, 2000, p.12. 


\section{Edmilson Menezes}

e mesmo perigosa. ${ }^{27}$ Eis o alvo preciso ao qual vai se dirigir a crítica de vários educadores e filósofos: apesar de sua solidez, a Ratio da Companhia funcionava muito mais como fonte de domínio e de ortodoxia do que de incentivo ao espírito competente e livre. A produção do conhecimento gerado no seio da Igreja era, enfim, doutrinária e contra os interesses da cidadania, que devem ser os interesses do Estado. Ela tornou-se infértil na produção da dignidade e do progresso dos homens e, por essa razão, deveria ser substituída no controle efetivo da formação dos membros da nação. Anuncia-se o que será, pouco tempo depois, a Escola laica. Na verdade, à educação reclamava-se o seu abandono preceptoral, para que se tornasse cada vez mais institucional, ou seja, que assumisse uma feição escolar.

Assim, a educação precisava deixar de ser tarefa exclusiva para ir ao encontro da sociedade, carecia expandir-se para além dos pequenos e aristocráticos círculos. A Igreja possuía um plano universal de salvação, mas, o seu projeto, enquanto zeladora do ensino formal, estendia-se apenas a um quadro bastante limitado. Se a Aufklärung e as Lumières guardam traços distintos em sua crítica ao espírito religioso, em um ponto elas parecem se aproximar: é crucial separar Igreja e Escola. Essa é uma ideia nevrálgica às reflexões não só francesas, mas, igualmente, alemãs. A condenação à ingerência eclesial no ensino, antes mesmo daquela expressa por Diderot, já encontrava espaço nas páginas escritas pelo grande educador alemão Basedow. A vigilância e controle das escolas, defende ele, devem sair das mãos dos eclesiásticos, "que, frequentemente, não possuem o conhecimento exato das necessidades públicas, a erudição sólida e ignoram a medida na qual as diferentes partes das ciências devem aparecer nos programas; e mesmo quando possuem essas qualidades, consideram suas funções

27. PINLOCHE, A. La réforme de l'éducation en Allemagne au dix-buitième siècle. Paris: Armand Colin, 1889, p. 2. O autor registra o depoimento de um pedagogo protestante do século XVI (J. Sturm) sobre os jesuítas e seu sistema educativo: "Eu me regozijo com a sua existência por dois motivos: primeiro, porque servem à nossa causa ao cultivar a ciência, pois eu vi quais autores explicam e quais métodos seguem, método tão semelhante ao nosso que diria ter sido a nós emprestado por eles; em seguida, porque nos obrigam a uma grande atividade e a uma grande vigilância se não queremos que trabalhem mais que nós e fundem mais escolas eruditas." O registro se completa com o depoimento de Bacon: "Tomai como exemplo as escolas dos jesuítas, pois não existiu, até agora, nada de melhor" (apud: Idem, Ibidem). 
antes como uma questão religiosa do que como uma questão de Estado: ora, essas devem ser, antes de tudo, uma questão de Estado". ${ }^{28}$ Transferidas as funções educativas para o Estado, este conseguirá opor às querelas doutrinárias, deturpadoras da educação civil, os interesses do próprio Estado, que, naquele momento, como em outras situações históricas, destoavam daqueles da Igreja. "Os costumes e, por conseguinte, a educação e a instrução, estão corrompidos ao extremo", lembrava o pedagogo. "As Igrejas rivalizaram na ortodoxia e não foram bem sucedidas, por consequência, em dar quantidade suficiente de luzes e virtudes aos cidadãos. É preciso que os Estados se curem eles mesmos quando se sentirem doentes, pois os médicos ordinários não conhecem a natureza de seus males, ou simplesmente não o curam. ${ }^{129}$ A radiografia de Basedow expõe e aguça as fragilidades do ensino religioso com o objetivo de mostrar que aquela que vinha para curar os males, também padecia deles. Um doente não pode curar outro: melhor é que o Estado cure-se ele mesmo recorrendo a procedimentos laicos e naturais; e como o maior dos males é o mal social, um bom remédio consiste em transformar a moral religiosa em uma moral cívica e racional. "Até o momento, as diferentes Igrejas foram as únicas a tomar para si os cuidados com a instrução moral da juventude, sobretudo dos jovens do povo, e as escolas estão ainda, em grande parte, dirigidas pelos eclesiásticos. Será que o Estado não tem interesse em assegurar-se de que aqueles que ocuparão, em idade adulta, certas posições civis sejam suficientemente instruídos de seus deveres e funções?". ${ }^{30}$ Os Estados não podem abandonar a educação às mãos estranhas aos interesses das nações. O apostolado deve ocupar-se de seus quadros (sacerdotes, padres, etc.) na clausura e nas igrejas; a escola, sob a proteção estatal e obedecendo ao princípio da publicidade, deve preparar os cidadãos que representarão o Estado nas diversas funções a eles atribuídas. Ao primeiro, corresponde ensinamentos místicos e religiosos, teologia e dogmática à segunda, ensinamentos científicos, moral laica e princípios cívicos.

Enfim, para Basedow, o ensino público é o instrumento mais útil para a formação daqueles que zelam pelo bem comum. Como ao Estado

28. BASEDOW, J.B. Methodenbuch (1770), IX, § 1. In: PINLOCHE, A. Basedowet le pbilantbropinisme. Paris: Armand Colin, 1889, p. 206.

29. Idem, Ibidem

30. Idem, p. 205. 


\section{Edmilson Menezes}

cabe a guarda de tal bem, compete-lhe, da mesma forma, a viabilização, o custeamento e a gerência dos bancos escolares:

Sensatos patriotas do gênero humano e das nações, vós estais de acordo comigo quanto ao fato de que a felicidade do Estado não pode estar separada daquela dos particulares, que essa felicidade é proporcional à virtude pública, que a virtude pública depende, em geral, da educação de todos, e, em particular, da instrução daqueles que, pertencendo às classes elevadas, dirigem os costumes e decidem a sorte de tantos, que, enfim, uma educação e uma instrução que têm por resultado a produção da virtude pública, devem ser submissas, não somente a regras constantes, mas, ainda, a regras que possuem necessidade de serem modificadas segundo o tempo, os países e as formas de governo. Vós estais de acordo comigo quanto ao fato de que o ensinamento público é um dos instrumentos mais úteis e mais seguros para fazer ou manter a felicidade de um país, conquanto permita suas singularidades e que, por conseguinte, a vigilância constante desse instrumento e de seu emprego pertence diretamente a um conselho patriótico, do qual o soberano poderá escutar as representações com a mesma frequência com que escuta os conselhos das finanças, da guerra e da justiça. ${ }^{31}$

Enquanto um aspecto fundamental da vida civil, a educação é transformada em questão de Estado e, com isso, o monopólio que se estabeleça sobre ela só poderá ser de natureza pública. Mesmo os que se pretendem à frente da regra dos costumes e da política deverão subordinar-se ao interesse coletivo, aprendido e assimilado durante uma formação escolar pública.

Será, no entanto, a filosofia ilustrada, como, por exemplo, na escrita de Diderot, que fornecerá a definição da educação pública como sendo a educação universal, isto é, que não é apenas coletiva ou sinônimo de preparação de quadros para o Estado; muito mais do que uma oposição ao ensino eclesial, o ensino público impõe-se como uma obrigação estatal, como condição de cidadania: "Eu penso", diz ele, "que se deveria fornecer na escola uma ideia de todos os conhecimentos necessários a um cidadão [...]."32 Fica identificada, dessa maneira,

31. Idem, p. 204.

32. DIDEROT, D. Plan d'une université pour le gouvernement de Russie ou de l'éducation publique dans toutes les sciences (1775-1776), p. 421. Depois de escritas essas páginas, passaram-se mais de dois séculos. Mesmo assim, não há como, para 
uma tarefa essencial da escola. A cidadania compreende uma horizontalidade das relações sociais visando o bem comum, e a escola deverá ensinar os princípios que tornam a vida social uma vida de responsabilidade civil: "É bom conheceras diferentes relações pelas quais cada um contribui para o proveito da sociedade." ${ }^{33}$ Longe de tomar para si tal encargo, a antiga escola não fazia "nenhuma distinção entre o que importa a todos saber e o que interessa apenas a poucos. ${ }^{134}$ Uma simples operação mental é o suficiente, pensa Diderot, para demonstrar a inversão lesiva porque passava a educação:"[...] seria tão cruel quanto absurdo condenar à ignorância as condições subalternas da sociedade. Em todos há conhecimentos dos quais não saberíamos nos privar sem consequências. O número de casebres e de outros edifícios particulares estando para o de palácios na proporção de dez mil para um, há dez mil para apostar contra um que o gênio, os talentos e a

uma mente vigilante, negar que as palavras de Diderot podem nos conduzira uma infeliz constatação: entre nós, a escola ainda se bate para levar um pouco de conhecimento, em muitos casos, rudimentar, aos bancos nos quais se encontram os que deveriam ser os futuros cidadãos. Enquanto isso, nutrimo-nos de fórmulas canhestras, ou, o que é pior, de fórmulas falsamente cidadãs que buscam, em nome de uma pseudo politização, atender a interesses discutíveis de "movimentos sociais" acalentados pela ânsia de um quinhão de poder, para, em seguida, se essa ventura chegar, esquecer, candidamente, seu clamor "social" e "igualitário". Assim, fundam-se pedagogias telúricas, perspectivas interdisciplinares, metodologias multiculturais, inventam-se inteligências afetivas, etc: abusos de princípios, em sua origem ricos, que se transformam em instrumentos de ilusão intelectual e engodo pedagógico. Se uma veia política um dia ali compareceu, ela, ao menor indício de realce, não mais estima a cidadania e não mais associa educação, política e ética. Para educar, nesses moldes, é necessário esquecer os liames que unem ciência e método; obstinação e progresso; competência e reconhecimento. Outra vez as palavras de Diderot parecem bem-vindas: "O templo da glória está situado no cume de um rochedo escarpado, ao lado daquele da ciência. O caminho que conduz à virtude e à felicidade é estreito e penoso. O trabalho o encurta e abranda, por meio do bom método; procuremo-lo. Não nos enganemos, nem aos alunos: seus progressos só podem ser frutos da obstinação. Que os professores não esmoreçam com o serviço que prestam à pátria e que os alunos sejam encorajados pela esperança da recompensa que os aguarda: a consideração pública." (Idem, p.432).

33. Idem, Ibidem.

34. Idem,p.431. 
virtude sairão antes de um casebre do que de um palácio." ${ }^{135} \mathrm{O}$ que é público iguala-se ao prioritário para a maioria. "Falando propriamente, uma escola pública é instituída para os filhos dos pais cujos módicos rendimentos não são suficientes para gastar com uma educação doméstica, que suas funções diárias não permitiriam o cuidado de supervisionar; é o grosso da nação." ${ }^{136}$ Se as despesas do Estado são financiadas pelo "grosso da nação", nada mais justo do que concerni-lo na demanda preferencial da escola e de ensino público. Enganar-nos-íamos se víssemos ai apenas um brado deslocado. Diderot encontra-se em sintonia com o seu tempo e pede à educação vigente contas de um benefício que ela mantém apenas em mão única. Igualmente a uma série de pensadores ilustrados, alguns dos quais já aqui citados, o autor de A religiosa insiste: a maior difusão dos benefícios educacionais só poderia se dar a partir do momento no qual a educação deixasse o domínio privado:

É que nada luta com mais obstinação contra o interesse público do que o interesse particular, é que nada resiste mais fortemente à razão do que os abusos inveterados; é que a porta das companhias e comunidades está fechada à luz geral, que há muito tempo faz inúteis esforços contra uma barreira erguida durante vários séculos; é que o espírito de corporação permanece o mesmo, enquanto tudo muda ao seu redor ${ }_{i}$ é que os maus estudantes se transformam em maus mestres, que preparam, em seus alunos, mestres semelhantes a $\mathrm{si}_{i}$ dessa maneira, se estabelece uma perpetuidade da ignorância tradicional, consagrada pelas velhas instituições; enquanto os conhecimentos brilham em toda a parte, as espessas sombras da ignorância continuam a cobrir esses asilos de disputa barulhenta e inútil. ${ }^{37}$

Se o caráter de affaire público caracteriza a educação moderna, ela possui, do mesmo modo, enquanto pertencente ao interesse compartilhado, um caráter político, militante. À erudição e ao cultivo da perfumaria letrada, herdeiros legítimos do modelo pedagógico tradicional, os filósofos ilustrados opõem as luzes da razão que, por sua marca universal e lógica, são capazes de desmascarar o interesse no cultivo da ignorância do "grosso da nação".

35. Idem, p. 433.

36. Idem, p.434.

37. Idem, p. 440. 
A filosofia do iluminismo, ao incluir a educação em seus alvos de interesse, transmite à posteridade a ideia de que as opções nesse sector não se dão sem que esteja em jogo uma implicação política e um domínio público de discussão. Esse último, amplia-se e extrapola a condição intelectual de discurso e polêmica para se tornar um requisito social: assim como a discussão pode ser facultada a todos que dela queiram participar, também a possibilidade de educar-se pode estender-se a todos. Tanto para a inserção no debate, como no ato de formar-se, de penetrar no mundo da cultura, um requisito é exigido, a liberdade. O domínio intelectual, por conseguinte, pede a liberdade de expressão, e a tarefa educativa pede a liberdade de ação, e ambos requisitarão a liberdade política. Assim como for o Estado assim será a educação. "Não há educação possível num governo despótico; ela deve tornar-se uma parte integral da política, a duplo título: a política forma a educação, e a educação forma a política. ${ }^{138}$ Não mais um affaire livresco, mas um veículo de formação para a cidadania. A educação precisa ser um affaire público respaldado pelo Estado, a fim de que a liberdade requerida para um processo tão importante, não circunscrito à instrução, atinja o seu objetivo principal: formar homens livres para o exercício da vida civil. "A arte de formar os homens está, em todo País, tão estreitamente ligada à forma de governo, que talvez não seja possível fazer nenhuma modificação significativa na educação pública, sem fazê-la na própria constituição dos Estados. ${ }^{139}$ Publicidade, política e educação serão, depois das Luzes, um trinômio inseparável. Mas essa união deverá ser selada pelo princípio da autonomia e, para isso, além de uma educação que seja pública e garantida pelo Estado ela deve subordinar-se a princípios éticos: que esperar de um povo entre o qual só podemos citar como honestos aqueles que se preparam para o sacerdócio? A moralidade não é um patrimônio da Igreja, mas um fruto da razão e, por isso mesmo, cabe numa educação que vise o bem comum e a convivência política.

\section{Kant: Esclarecimento e Educação Moral}

Kant inicia suas notas sobre a pedagogia com três proposições, que giram em torno da importância atribuída à educação na constitui-

38. HAZARD, P. La pensée européenne au XVIIIe. Siècle de Montaigne à Lessing, p. 198.

39. HELVÉTIUS, C-A. De l'esprit. (1758), (Discours IV, chapitre XVII - De l'éducation). Paris: Fayard, 1988, p. 553. 


\section{Edmilson Menezes}

ção da humanidade: "O homem é a única criatura que deve ser educada. Por educação (Erziebung) entende-se os cuidados (alimentação, entretenimento), a disciplina (Zucht) e a instrução com formação (Bildung)." ${ }^{40}$ Em seguida: "O homem só pode tornar-se homem pela educação. Ele é aquilo que a educação faz dele." ${ }^{141}$ Por fim, diz o filósofo, "é algo entusiasmante pensar que a natureza humana será sempre melhor desenvolvida pela educação e que podemos chegar a doar a esta última uma forma que convenha à humanidade. Isto nos abre uma perspectiva para uma futura espécie humana mais feliz. ${ }^{142}$ Que a educação esteja num plano destacado se justifica porque os nexos educativos estão em primeiro lugar, tanto cronologicamente - na história do indivíduo empírico - como logicamente - a consciência de si constituindo-se em relação ao outro. E, se educar significa, de acordo com a filosofia esclarecida, conduzir para a consciência de si e para a afirmação da liberdade, reconhecendo a outras liberdades a mesma condição de exercício, é porque o princípio filosófico foi transposto para o nível pedagógico. À primeira vista, poderíamos pensar num grande poder conferido à educação, como, aliás, é próprio ao espírito da época ${ }^{43}$. Por seu intermédio, o homem torna-se o que é, progride e pode se fazer mais feliz. A humanidade, trilhando os caminhos abertos pela educação, encontrará dias melhores, nos quais apaga, a cada passo, os traços de brutalidade, próprios de sua natureza. Por ser, no início, rude, e a barbaridade uma marca difícil de ser suprimida, o homem é o único animal que precisa de um mestre, pois ele, a partir do momento em que vive em sociedade, abusa de sua liberdade em relação aos demais. "Mas, onde buscar esse mestre? Em lugar algum fora da natureza humana. Ora, esse mestre, por seu turno, é, como ele [o homem], um animal que precisa de um mestre." ${ }^{\prime 4}$ Do mesmo modo, "é preciso assinalar que os homens são educados por outros homens

40. KANT, I. Über Pädagogik. AK IX, 441.

41. Idem, p. 443.

42. Idem, p. 444 .

43. "eu creio poder afirmar que nove entre dez homens que conhecemos, são o que são, bons ou maus, úteis ou inúteis, por causa da educação. É a educação que faz a diferença entre os homens." LOCKE, J. Some Thoughts concerning Education (1693), pp. 6-7.

44. KANT, I. Idee zu einer allgemeinen Geschicbte in weltbürgerlicher Absicht. (6a. Proposição), AK VIII, p.23. 
que, por sua vez, foram, também, educados. ${ }^{\prime \prime 5} \mathrm{O}$ detentor da tarefa de educar é também um homem, afetado pela grosseria de sua natureza, que deve produzir no outro aquilo de que ele próprio tem necessidade. Por isso, o homem desvia-se constantemente de sua destinação e precisa retomar de onde parou. $\mathrm{O}$ otimismo inicial passa, então, a outro matiz. Por mais nobre que seja o início da filosofia da educação kantiana, ela cede à evidência do seguinte fato: a educação presente está longe daquele ideal filosófico. O entusiasmo do progresso só pode ser um entusiasmo racional e sua proposta educativa vincula-se à condição de uma ideia: ${ }^{46}$ "o projeto de uma teoria da educação (Theorie der Erziehung) é um nobre ideal, e mesmo que não estejamos

45. KANT, I. Über Pädagogik, p. 443. Ver também Antbropologie, AK VII,325.

46. O entendimento é a fonte da experiência (quanto à forma) graças às categorias e aos princípios transcendentais, e a razão é a fonte das ideias, dos conceitos puros da razão. Esses aparecem por causa de uma "dialética" especial, como os conceitos dos objetos conhecidos. O incondicionado, a instância clarificadora da totalidade das condições, ao qual se remetem as ideias, parece ser objeto de conhecimento. Mas, as antinomias da razão mostram como as ideias não podem, de forma alguma, ser consideradas enquanto conceito dos objetos. No seu uso transcendental, porque ultrapassam os limites da experiência, as ideias revelam-se contraditórias, ilusórias. Quando as percebemos, no entanto, como conceitos não "constitutivos", mas "regulativos", pontos de vista superiores da elaboração e da sistematização da matéria empírica já intelectualmente determinada, regras para o processo de conhecimento, tal como ele progride em todos os sentidos, então as ideias têm um valor eminente. Elas são fecundas científica e filosoficamente, mesmo se constituem apenas "ficções heurísticas" às quais nada corresponde na realidade. As ideias partem do todo incondicionado e orientam a investigação, que a ele se dirige, para demonstrar, assim, que nenhum limite atingido pela análise ou pela síntese pode ser considerado como último e intransponível. O todo absoluto da experiência não é dado. Mas, ele volta ao pensamento que vai buscá-lo mesmo sem a possibilidade de chegar, de modo efetivo, a um termo. Isto, precisamente, porque a ideia, como conceito de um maximum, não pode jamais ser dada in concreto. É forçoso, entretanto, pensar e investigar como se o incondicionado fosse dado enquanto ponto de partida ou de chegada do conhecimento (ou da ação). Somente as ideias tornam possível uma coerência sistemática da experiência. Cf. KANT, I. Kritik der reinen Vernunft, AK III, B 367 e segs.. 


\section{Edmilson Menezes}

em condições de realizá-lo, ele não pode ser considerado danoso. Uma ideia não é nada mais do que o conceito de uma perfeição que ainda não é encontrada na experiência."47

Kant, ao conferir um caráter de ideia à educação, ou seja, ao the propor uma filosofia, previne-se contra as previsões incautas. A educação do homem encontra-se num terreno que inspira cautela, e no qual as antevisões para a ação livre, com frequência, redundam em grandes ilusões. Quando associada ao progresso, a educação não comporta senão uma garantia prática. $\mathrm{O}$ projeto filosófico de uma educação para a humanidade é apresentado como uma hipótese ou um pressuposto, quer dizer, uma máxima do julgamento cuja validade prática repousa sobre o dever que cada um se outorga em vista da posteridade, e, portanto, sobre o dever do gênero humano para consigo mesmo. Não se pode pedir à educação nenhuma prova objetiva do progresso moral e, quanto aos progressos da educação, nada pode garanti-los a não ser a educação ela mesma. Por que, então, o homem precisa de educação? Justamente por ser livre. "Porque ele é livre, o homem é um ser que possui um devir e, de todos os seres, ele é o único que, de modo real, existe temporalmente." ${ }^{48}$ Por causa do seu estatuto de ser livre, o homem, originalmente, não é nada; sua liberdade permite que seja traçado um caminho que, sendo percorrido, conduz o homem à formação de si mesmo. O percurso the revela as condições e os instrumentos com os quais ele se aperfeiçoa por meio de escolhas livres; mas, esse manancial de perfectibilidade possui pouco de espontâneo e quase tudo é fruto de aprendizagem. Por isso,

[... a educação é uma arte, da qual a prática deve ser aperfeiçoada por muitas gerações. Cada geração, instruída pelos conhecimentos das precedentes, acrescenta algo mais quando se trata de estabelecer uma educação que desenvolva, de maneira conclusiva e proporcional, todas as disposições naturais do homem e, assim, conduza a espécie humana inteira à sua destinação. A providência quis que o homem fosse obrigado a produzir o bem a partir de si próprio: 'Vá pelo mundo, poderia bem o Criador falar ao homem, eu te dei todas

47. KANT, I. Über Pädagogik, p. 444.

48. PHILONENKO, A. Kant et le problème de l'éducation. In: KANT, I. Réflexions sur l'éducation. Paris: Vrin, 1967, p. 26. 
as disposições para o bem. Cabe a ti desenvolve-las e, dessa manei$\mathrm{ra}$, tua felicidade e tua infelicidade estão sob a tua dependência'. ${ }^{49}$

O próprio homem deve desenvolver as suas disposições, elas não foram nele colocadas completamente acabadas. Na verdade, são simples disposições sem a marca distintiva da moralidade. "Aperfeiçoar-se, cultivar-se e, se é má a sua natureza, desenvolver em si a moralidade, é o que deve (soll) fazer o homem. Uma reflexão madura nos mostra o quanto isso é difícil. Assim, a educação é o maior e o mais difícil problema que possa ser proposto ao homem. ${ }^{\prime 50}$ Só através das gerações sucessivas os obstáculos podem ser minimizados, e até suprimidos. Essa filosofia da educação deposita todas as suas esperanças num continum, num intercâmbio incessante entre as gerações: elas deixam suas experiências e seus conhecimentos para a seguinte e, assim por diante, de maneira sempre enriquecida. É por essa condição de ideal que a educação deve estar voltada para o futuro: "não se deve educar as crianças somente de acordo com o presente estado da espécie humana, mas em conformidade com seu estado futuro possível e melhor, quer dizer, de acordo com a ideia de humanidade e sua destinação." ${ }^{\prime \prime 1}$ Contudo, como nos lembra Reboul ${ }_{1}^{52}$ o progresso da espécie humana não significa o progresso dos homens, ao menos sobre o plano moral.

Visto isoladamente, no campo moral, o homem não se encontra isento de suspeitas. Kant reconhece que os pendores presentes no homem comprometem as iniciativas em prol da construção do melhor, elas esbarram no egoísmo. Daí o imperativo moral de nunca considerar o outro como meio e sim como fim..$^{53} \mathrm{O}$ outro é fim, enquanto membro de um todo, por isso deve ser respeitado. $\mathrm{O}$ todo exige que as máximas, sempre assumidas no foro privado e íntimo, revelem-se publicamente e sejam avaliadas: o egoísmo só é possível quando confinado. A primeira tendência é a de subordinar o indivíduo à coletividade. Porém, há um aspecto interessante a ser marcado: o indivíduo é uma fase e deve encaminhar-se para a condição de pessoa, isto é, de

49. KANT, I. Über Pädagogik, p. 446.

50. Idem, ibidem.

51. Idem, p. 447.

52. REBOUL, O. Kant et le problem du mal. Montréal: Les Presses de l'Université de Montréal, 1971, p.226.

53. Cf. KANT, I. Grundlegung zur Metapbysik der Sitten, AK IV, pp. 437-438 
sujeito moral. Se o homem conhece, pela razão pura, importa, sobretudo, saber o que fazer deste conhecimento no seu encaminhamento moral, orientado pela razão prática. Para tanto, ele precisa do concurso geral ${ }_{i}$ de maneira isolada, o indivíduo não conseguiria fazê-lo, porque a moral pressupõe, necessariamente, uma ação na qual o outro é envolvido de modo direto ou indireto. ${ }^{54}$ Contudo, não presenciamos uma dissolução do individual no conjunto. Kant reconhece uma estima de si. Estimar-se é um dever: "a estima de si é um dever do homem para consigo mesmo." ${ }^{155} \mathrm{O}$ querer-se representa um dos primeiros passos no auto conhecimento e no reconhecimento do mundo coletivo. Mas, devido à sua natureza, esta autoestima pode deteriorar-se em egoísmo moral, "o que reduz todos os fins à sua própria pessoa", e o alvo da razão é prejudicado. À moral acompanha um elemento antropológico. "A filosofia prática (ciência prescrevendo como o homem deve se conduzir) e a antropologia (ciência descrevendo como o homem se conduz realmente) são intimamente ligadas. A primeira não pode se justificar (bestehen) sem a segunda. ${ }^{157} \mathrm{O}$ homem é destinado pela razão a viver em sociedade com outros homens, e nela se cultivar, civilizar-se e se moralizar. Por maior que seja o seu pendor animal a se entregar passivamente às inclinações do conforto e do bem viver pessoal, chamados por ele felicidade, é lá, no coletivo, que o homem se torna ativamente digno da humanidade, ao combater os obstáculos oriundos de sua natureza. O homem conhece, pela razão pura, o ideal de bumanidade, por meio do qual ele se compara e recebe o critério da apreciação de si mesmo. O campo moral recorre, assim, à antropologia, para verificar os bomens reais, e desta forma não tornar o fim da razão algo sem referencial e utópico. Do que se tem, busca-se a perspectiva futura. $O$ vínculo tenso entre razão e natureza encontra na história uma via de conciliação. Nela, o indivíduo se transforma em sujeito, pessoa.

Para entender o mundo, não basta uma atitude intelectual espontânea. É imprescindível partir de um alto senso de coletividade: as

54. Ver MENEZES, E. Aufklärung: uma filosofia da educação para a esperança. In: História e esperança em Kant. Aracaju/ São Cristóvão: Fundação Oviêdo Teixeira/ Editora da Universidade Federal de Sergipe, 2000.

55. KANT, I. Metapbysik der Sitten, AK VI, p. 435.

56. KANT, I. Antbropologie, § 2, p. 130.

57. KANT, I. Vorlesungen über Moralpbilosopbie. AK XXVII, p. 244. 
liberdades individuais devem disciplinar-se em vista de um bem maior, o coletivo. O seu primeiro passo é dado pela subjetividade que se reconhece autônoma e digna: "a autonomia é o fundamento da dignidade humana. ${ }^{158}$ A dignidade e a autonomia também requisitam a educação; ela deve acentuar o seguinte posicionamento: "o homem possui interiormente uma dignidade que o enobrece aos olhos de todas as outras criaturas, e é seu dever não renunciar a esta condição presente em sua pessoa." ${ }^{159}$ Pela educação compreendemos que o mundo não está centrado em nós, nem podemos trazê-lo inteiro conosco, mas dele somos dignos enquanto cidadãos. A isto não podemos renunciar, sob pena de renegar o nosso estatuto humano. À moral e à antropologia acrescenta-se a educação. Construir o sujeito moral na história requer um aspecto pedagógico, uma disciplina das liberdades em vista da autonomia, e, em consequência, do respeito à sua dignidade e à dignidade do outro. "Pela educação moral o homem adquire um valor relativo à espécie inteira"60; esse tipo de educação dispõe-se a formara pessoa digna, sujeito cujas ações são suscetíveis de uma imputação. A personalidade moral nada mais é do que a liberdade de um ser racional submissa a leis morais autoestabelecidas. No tocante aos deveres do homem para consigo, considerado como ser moral, eles residem na forma do acordo das máximas de sua vontade com a dignidade da humanidade em sua pessoa. Isto quer dizer que ele não pode abdicar do privilégio de agir segundo princípios, ele não pode renunciar à liberdade.

Com efeito, a educação moral é o coroamento propriamente dito do processo educacional. Ela compreende a habilidade, a prudência e a moralidade. No que concerne à habilidade, deve-se atentar para o que é sólido e não para o que é efêmero. Não se pode ter a aparência de possuir um conhecimento das coisas que não se consegue, em seguida, realizar. A seriedade deve ter seu lugar destacado no desenvolvimento da habilidade e torna-se, pouco a pouco, um hábito na forma de pensar. A prudência consiste na arte de aplicar nossa habilidade ao homem, ou seja, saber usar os homens em nosso próprio proveito ${ }^{61}$. Por fim, a moralidade diz do caráter, ou seja, diz da firmeza e da de-

58. KANT, I. Grundlegung zur Metapbysik der Sitten, p.436.

59. KANT, I. Über Pädagogik, p. 488.

60. Idem, p. 455.

61. Ver KANT, I. Antbropologie §85, p.272, Kritik der reinen Vernunft, B 776. 


\section{Edmilson Menezes}

terminação com a qual queremos qualquer coisa, e os meios pelos quais a realizamos. ${ }^{62}$ A educação do corpo e a educação intelectual forneceram a base para a habilidade, assim como a escola desenvolveu os princípios da prudência e, ao termo do desenvolvimento, todos os momentos da educação se reúnem e integram-se no seio da educação prática. Ao tornar-se moral, a educação torna-se total.

$\mathrm{O}$ homem pode ser simplesmente adestrado (dressiert), dirigido ou instruído de forma mecânica. Tudo isso pode ser feito em nome de um princípio educativo, mas não é suficiente. "Com efeito, importa, antes de tudo, que as crianças aprendam a pensar." 63 Saber bem pensar é poderoso instrumento de liberdade e, como tal, difícil em sua consecução. Podem nos servir de orientação as seguintes máximas: a) pensar por si mesmo - máxima de um espírito desprovido de preconceito (Vorurteil), livre; b) pensar se colocando no lugar do outro - máxima de um pensamento ampliado, desenvolvido; c) pensar de acordo consigo mesmo - forma consequente do pensamento. ${ }^{64} \mathrm{~A}$ primeira máxima, carro chefe das demais, é a do homem esclarecido. Uma razão passiva, trancada em preconceitos, é propensa à superstição e,

62. KANT, I. Über Pädagogik, pp. 486, 487.

63. Idem, p. 450. Anos mais tarde, Hegel dirá, a propósito do ensino filosófico: "Não somente tornou-se um preconceito do estudo filosófico, como também um preconceito da pedagogia - e aqui de uma maneira até mais estendida - que, quando se exercita o pensar por si mesmo, em primeiro lugar, a matéria não tem importância; e, em segundo, o fato de aprender é oposto ao fato de pensar por si mesmo: ainda que, na realidade, o pensamento só possa se exercer sobre uma matéria que não é um produto da imaginação ou uma representação sensível ou intelectual, mas um pensamento; e que, em seguida, um pensamento somente pode ser conhecido pelo fato mesmo de que ele é um pensamento. Segundo um erro comum, um pensamento traz a marca de que ele é um pensar por si próprio apenas quando ele se afasta do pensamento de outros homens; então, a conhecida fórmula, segundo a qual o novo não é verdadeiro e o verdadeiro não é novo, tem o hábito de encontrar, em tal caso, sua aplicação. - De lá, originou-se essa mania que faz com que cada um queira ter seu próprio sistema, e que quanto mais um ideia é absurda e louca, mais ela é tida por original e excelente, precisamente porque ela demonstra, assim, sua originalidade e sua diferença com os pensamentos anteriores." HEGEL, G.W.F. Hegel an von Raumer, 02. 08. 1816. In: Briefe von und an Hegel (Band II: 1813 1822). Hamburg: Felix Meiner, 1953.

64. Cf. KANT, I. Kritik der Urteilskraft, §40, AK V, 294; Anthropologie, § 43, p. 200. 
libertar-se dela, é o verdadeiro Esclarecimento. ${ }^{65} \mathrm{O}$ supersticioso é cego, ele é levado à necessidade de ser guiado por outros; por conseguinte, ao estado de uma razão cativa, e acaba colocando, naquilo que esperamos chegar de maneira não natural, uma confiança maior do que naquilo que é suscetível de explicação segundo as leis naturais. ${ }^{66}$ O homem das Luzes projeta seus fins de comum acordo com a natureza. Na história, por exemplo, ele não mais procura os recursos divinos em seu favor e faz da educação das gerações a nova base do progresso. O cultivo do espírito permite a formação de uma consciência moral autônoma, livre das superstições. Nenhum deus, nenhum ser de uma espécie superior veio à terra encarregar-se da educação dos primeiros homens, nem de sua posteridade. É a razão pela qual não se pode afirmar terminantemente do que o homem é capaz; suas capacidades se revelam simultâneas ao seu desenvolvimento.

Entretanto, formar uma maneira autônoma de pensar ainda requer esforços de muitas gerações. Não vivemos uma era cuja observância à lei se dê por puro respeito, ou fazemo-la por conformidade. A educação também espelha essa realidade e dirige-se para a conformidade à lei, é a educação formal que prepara para a cidadania ${ }_{i}$ mas, orienta-se, de outra parte, como educação dirigida para o puro respeito à lei, é ideal pedagógico que deve nortear os passos da primeira: "É necessário velar pela sua moralização. $\mathrm{O}$ homem não deve ser hábil a toda sorte de fins, ele deve, também, adquirir a disposição de espírito que lhe faça escolher somente bons fins. Bons são os fins que recebem, necessariamente, a aprovação de cada um e que podem ser, ao mesmo tempo, os fins de cada um." ${ }^{\prime \prime 7}$ Uma ação praticada por dever tem seu valor moral, não no propósito que com ela se quer atingir, mas na máxima que a determina, não depende, portanto, da realidade do objeto da ação, mas somente do princípio do querer segundo o qual a ação, abstraindo de todos os objetos da faculdade de desejar, foi praticada.

Quando se fala de valor moral, não é das ações visíveis que se trata, mas dos seus princípios. Embora as primeiras sejam importantes, elas são determinadas pelos segundos e possuem um valor relativo em termos de julgamento moral. Tudo isso corrobora para que as ações

65. KANT, I. Kritik der Urteilskraft, §40, AK V, 294

66. Cf. KANT, I. Der Streit der Fakultäten, AK VII,48 e ss.

67. KANT, I. Über Pädagogik, p. 450. 


\section{Edmilson Menezes}

moralmente relevantes tornem-se difíceis de serem implementadas e avaliadas, podendo-se, assim, vislumbrar duas instâncias de determinação da ação: a moralidade e a legalidade. O que é essencial no valor moral das ações é que a lei moral determine imediatamente a vontade. Se a determinação da vontade acontece em conformidade à lei moral, mas só por meio de um sentimento, não importa de que espécie, por conseguinte, não por causa da lei, a ação conterá certamente legalidade, mas não moralidade. ${ }^{68}$ A lei moral, ela própria, deve ser o móbil, o motivo do querer. Tem-se a moralidade quando a ação é cumprida por dever. Tem-se, ao contrário, a pura e simples legalidade, quando a ação é conforme ao dever. Dito de outra forma, a legislação moral é aquela que não admite uma ação efetuada segundo as inclinações e os interesses. De maneira diferente, a legislação jurídica aceita apenas a conformidade da ação à lei e não se interessa pelos seus móbeis determinantes. A pura moralidade se coaduna com uma vontade cujo respeito esteja voltado só para seus fins, isto é, uma vontade que não está determinada por atitude alguma e por cálculo interessado algum, mas apenas pelo respeito ao dever. Decididamente, não habitamos num mundo onde reine, de modo incondicional, a boa vontade.

O Direito, como elemento disciplinador das liberdades, consegue implantar a civilização, mas não a moralidade. Ele, na verdade, é um grande passo rumo a moralidade, embora não tenha ainda um caráter moral. Vivemos, consequentemente, uma época civilizada, mas não moralizada, ${ }^{69}$ a humanidade alcançou uma comunidade civil, política, mas ainda persegue uma comunidade ética. Sem, no entanto, a legalidade, oriunda da imposição do direito, é impossível vislumbrar o passo seguinte, ou seja, a moralidade. A tendência a refrear os seus impulsos transgressores, sob a aparência de uma conduta em tudo conforme à lei, pode, paulatinamente, produzir uma disposição interior para agir não só segundo a lei, mas também por respeito a ela, de tal modo que os homens não só se civilizam, como pouco a pouco, em certa medida, se moralizam. "Não uma quantidade sempre crescente da moralidade quanto a intenção, mas um aumento dos efeitos da sua

68. KANT, I. Kritik der praktischen Vernunft (I, 1, III). AK V, 71. Sobre a moralidade e a legalidade na doutrina do direito de Kant, ver BOBBIO, N. Direito e Estado no Pensamento de Emanuel Kant. Trad. de Alfredo Fait. Brasília: Editora Universidade de Brasília, 1984.

69. Cf. KANT, I. Über Pädagogik, p.451; Was ist Aufklärung?, AK VIII, 40. 
legalidade nos atos conforme ao dever, sejam quais forem os motivos que os ocasionaram", ${ }^{70}$ eis o que presenciamos na história, segundo Kant. Com efeito, o homem civilizado é o prenúncio do homem moral: "o homem, mesmo que ele não seja moralmente bom, é, entretanto, compelido a ser, por isso mesmo, um bom cidadão". ${ }^{71}$

O estado controla a legalidade, mas, sozinho, não consegue preparar cidadãos. É da educação formal essa tarefa: "aqui a educação pública (öffentliche Erziebung) revela suas vantagens mais surpreendentes. Nela aprende-se a medir suas forças e a limitação resultante do direito do outro. Nela não se goza de nenhum privilégio, porque se encontra por toda a parte resistência e só se pode destacar pelo mérito. Ela fornece a melhor imagem (Vorbild) do futuro cidadão."72 Há uma educação formal que prepara o indivíduo para a cidadania: ela deve ensinar-lhe a convivência pacífica com os outros, isto é, com a liberdade dos demais. Ela é a primeira a começar ser transmitida pela cultura da prudência, para, na sequência, o indivíduo encontrar a formação civil, pois ele adquire um valor público. O educando deve ser preparado para agir conforme a lei e tornar-se membro efetivo da sociedade civil. Os instrumentos de acesso à cultura escrita e os demais componentes de uma formação cívica, são, pelo estatuto público, os primeiros sinais de igualdade e de reconhecimento na esfera social. $\mathrm{O}$ fato de todos poderem entrar, da mesma forma, em contato com os meios para melhor utilizar sua habilidade, antecipa a educação moral e, por conseguinte, o grande triunfo do ideal da Aufklärung: a autonomia. "Pela educação moral, o homem adquire um valor em relação a espécie humana", ${ }^{73}$ ele passa a não ser apenas cidadão, mas toma consciência de seu estado de ser livre. Se a educação formal preparou-o para a cidadania, a segunda prepara para a liberdade. Mas, uma ideia de humanidade orienta esta proposta moral: deve-se formar o caráter da pessoa em vista do puro amor ao dever. Tal ideia não permite que pensemos a formação moral como uma mera etapa, cronologicamente preestabelecida, ela perpassa todo o processo educacional e avança com as gerações: "Na educação atual, o homem não atinge inteira-

70. KANT, I. Der Streit der Fakultäten, p. 91.

71. KANT, I. Zum ewigen Frieden. AK VIII, 366.

72. KANT, I. Über Pädagogik, p. 454.

73. Idem, p. 455 
mente o objetivo de sua existência. ${ }^{.74}$ Cada geração instruída dos conhecimentos da precedente, estabelece uma educação que desenvolve as disposições naturais do homem e conduz a espécie à sua destinação.

A Aufklärung identifica-se profundamente com esse projeto educativo, porque seus ideais de humanidade e de autonomia, sem ele, estariam fadados à quimera. Transformando-se numa filosofia da educação, ela assume tal projeto como o veículo que levará a humanidade até o ponto de não precisar mais da autoridade externa e da superstição, como escudos da sua menoridade. Acreditar na possibilidade de um homem educado para a liberdade é o que permite estruturar a Aufklärung como um processo, do qual se vive apenas a aurora:

De imediato, nos apercebemos que se o Esclarecimento (Aufklärung) in thesi é fácil, in bypothesi, porém, é uma coisa difícil e longe de se realizar, por certo, não ser com sua razão passivo, mas sempre se dá sua própria lei é, na verdade, coisa bem fácil ao homem que quer ser conforme apenas ao seu fim essencial e não pretende conhecer o que ultrapassa o seu entendimento. Mas, como a aspiração a tal conhecimento é quase inevitável e como jamais faltarão os que pretendam, com muita segurança, poder satisfazer essa sede de saber, assim deve ser muito difícil manter ou produzir na maneira de pensar (sobretudo na pública) esse momento simplesmente negativo (que constitui o verdadeiro Esclarecimento). ${ }^{75}$

A educação exigida para levar a sociedade às Luzes é lenta e difícil, pois cada geração deve transmitir e aperfeiçoar os ensinamentos recebidos. Educar não significa, desta forma, limitar o trabalho pedagógico a uma técnica, ela consegue burilar o indivíduo, mas não é suficiente para preparar uma época para o exercício da cidadania: "É fácil, portanto, estabelecer nos sujeitos particulares o Esclarecimento (Aufklärung) por meio da educação; deve-se apenas começar cedo e habituar os jovens espíritos (jungen Köpfe) a esta reflexão. Contudo, esclarecer uma época é muito demorado, pois nos deparamos com muitos obstáculos exteriores que, por um lado, próibem e, por outro, dificultam esta espécie de educação. ${ }^{176}$ Os obstáculos externos aos

74. Idem, p. 445 .

75. KANT, I. Kritik der Urteilskraft, §40, p. 294.

76. KANT, I. Was beisst: Sich im Denken orientieren?, pp. 146-47. 
quais se refere o filósofo, dizem respeito a todos os mecanismos que contribuem para a heteronomia do pensar. Tanto o processo educativo quanto o esclarecimento podem ser afetados por eles, daí primar-se por conferir a ambos um caráter de interdependência que garanta um avanço contínuo e proporcional. Sem educação não há esclarecimento e vice-versa: "Com efeito, as luzes dependem da educação e, por sua vez, a educação depende das luzes." ${ }^{.77}$ É impossível pensar um homem esclarecido que não seja educado, também é difícil pensar alguém educado que não busque esclarecer-se, isto é, exercer livremente sua capacidade de pensar consequentemente. O círculo formado garante uma continuidade que aprimora incessantemente o ideal de humanidade. Por tudo isso, não seria demais afirmar, com Muglioni, ${ }^{78}$ que o problema da educação e o problema da história, em Kant, são uma mesma coisa. Os lentos passos, rumo ao melhor, viabilizam um conceito exato da estrutura educacional, porque uma geração lega à futura suas experiências e seus conhecimentos, e esta acrescenta alguma coisa e transmite à seguinte, formando, desta maneira, uma herança que define e avalia o progresso.

\section{Referências}

BACZKO, B. Une éducation pour la démocratie. Textes et projets de l'époque révolutionnaire. Genève: Droz, 2000.

BASEDOW, J.B. Methodenbuch (1770), IX, § 1. In: PINLOCHE, A. Basedowet le philanthropinisme. Paris: Armand Colin, 1889.

BOBBIO, N. Direito e Estado no Pensamento de Emanuel Kant. Trad. de Alfredo Fait. Brasília: Editora Universidade de Brasília, 1984.

CARADEUC DE LA CHALOTAIS, L-R. Essai d'éducation nationale ou Plan d'études pour la Jeunesse. Genève: Cl. \& Ant. Philibert, 1763.

D'ALEMBERT. Essai sur les éléments de philosophie (1759). Paris: Fayard, 1986.

D'HOLBACH, P-H. Th. "Lettres à Eugénie" (1768). In: .Oeuvres philosophiques. Paris: Alive, 1998.

. La contagionsacréeouHistoirenaturelle de la superstition" (1768).

In: . Oeuvres philosophiques. Paris: Alive, 1998.

77. KANT, I. ÜberPädagogik,p. 446.

78. MUGLIONI, J-M. "La philosophie de l'histoire de Kant".PbilosopbiePolitique, n. 2, 1992, p. 173. 
Le christianis medévoilé ou Examen des principes et des effets de la religion chrétienne (1756). In: Oeuvres philosopbiques.t. I, Paris: Alive, 1998. Préface.

DIDEROT, D. Plan d'une université pour le gouvernement de Russieou de l'éducationpubliquedanstoutes les sciences (1775-1776). In: Oeuvres Complètes. Paris: Garnier, 1875. t. III.

DUNN, J. The Political Thought of John Locke. Cambridge, uk: Cambridge University Press, 1969.

GUSDORF, G. L'avènement des Sciences Humaines au siècle des Lumières. Paris: Payot, 1973.

FABRICIUS, J. C. Von der Erziehung in sonderheit in Danemark. Dessau-Leipzig. In: KOENIG, H. Zur Geschicbte der Nationalerziebung in Deutscbland im letzten Drittel des 18. Jabrbunderts. Berlim: Akademie Verlag, 1960.

HAZARD, P. La penséeeuropéenne an XVIIIe. Siècle de Montaigne à Lessing. Paris: Fayard, 1963.

HEGEL, G.W.F. Briefe von und an Hegel (Band II: 1813-1822). Hamburg: Felix Meiner, 1953 . Grundlinien der Pbilosopbie des Rechts. Hamburg: Felix Meiner, 1955.

HELVÉTIUS, C-A. De l'esprit. (1758). (Discours IV, chapitre XVII - De l'éducation). Paris: Fayard, 1988.

HUSSERL, E. Die Krisis der europäischenWissenschaften und die transzendentale Phänomenologie. In:__Gesammelte Werke. Hagg: Martinus Nijhoff, 1976. Husserliana VI.

KANT, I. Kant's gesammelteSchriften. Herausgegeben von der Königlich Preussischen Akademie der Wissenschaften, v. 23.

LOCKE, J. Some Thoughts concerning Education (1693). In: The Works of Jobn Locke.London: ScientiaVerlagAalen, Darmstadt, 1963, v. IX.

MENEZES, E. Aufklärung: uma filosofia da educação para a esperança. In: História e esperança em Kant. Aracaju/ São Cristóvão: Fundação Oviêdo Teixeira/ Editora da Universidade Federal de Sergipe, 2000. MUGLIONI, J-M. La philosophie de l'histoire de Kant. PbilosopbiePolitique, n. 2, 1992.

PHILONENKO, A. Kant et le problème de l'éducation. In: KANT, I. Réflexions sur l'éducation. Paris: Vrin, 1967.

PINLOCHE, A. La réforme de l'éducation en Allemagneau dix-buitièmesiècle. Paris: Armand Colin, 1889. 
REBOUL, O. Kant et le problème du mal. Montréal: Les Presses de l'Université de Montréal, 1971

RIEM, A. Über Aufkärung (1788) In: BATSCHA, Z. Aufklärung und Gedankenfreibeit, Funfzebn Anregungen, aus der Gescbicbte zu lernen. Frankfurt: Suhrkamp, 1977.

ROUSSEAU, J-J. "Discours sur les sciences et les arts" (1750) In:

Oeuvres Complètes. Paris: Gallimard, 1996. t. III: Écrits Politiques (Bibliothèque de la Pléiade). 